\title{
Relaciones internacionales latinoamericanas: historiografías y teorías
}

\author{
EDMUNDO ANÍBAL HEREDIA*
}

Resumo: Este artigo busca estabelecer uma discussão historiográfica e teórica acerca do conceito América Latina, com o objetivo de analisar os limites e as possibilidades de sua aplicação nos campos científico e político, tendo em vista as relações internacionais na região, bem como sua inserção no sistema global.

Abstract: This article intends to establish a historic and theoretical discussion about the concept of Latin America, with the purpose of analyzing the limits and possibilities of its application in scientific and political fields, taking into account the international relations on the region, as well as its insertion in global system.

Palavras-chave: América Latina. Relações Internacionais. História.

Key words: Latin America. International Relations. History.

\section{Introducción}

La enunciación y la presentación de ciertos aspectos de la formación de la idea de América Latina, como una región en el mundo y en el largo tiempo histórico, tiene una directa implicancia en la comprensión de las relaciones establecidas entre las naciones que componen esta parte del continente americano.

Parece oportuna esta reflexión porque estamos pasando por un período de crisis en cuanto a la comprensión de América Latina como una unidad de análisis y como un espacio homogéneo aunque multiforme, y con identidad propia. Bueno es recordar que, luego de acuñado el término América Latina por Manuel Torres Caicedo con un sentido de solidaridad entre sus naciones, vino un período de afirmación de ese concepto con pensadores como José Martí, Manuel Ugarte, Manoel Bonfim o José Ingenieros, para llegar ahora, luego de un proceso con vicisitudes, a una etapa de

\footnotetext{
* Pesquisador do CONICET. Argentina.
} 
incertidumbre y hasta desconfianza o desinterés. Esta crisis se presenta como coyuntural, pero de nivel acentuado y por eso preocupante para la permanencia estructural de la idea. ${ }^{1}$ Por eso resulta interesante, en esta circunstancia, pensar en la vigencia de esa idea desde el punto de vista de la praxis política y desde su postulación como concepto político en el transcurso del tiempo.

Desde una dimensión histórica, debemos comenzar por reconocer el aporte de otras formas de conocimiento pertenecientes a varias ciencias sociales y humanas que contribuyeron a conformar la comprensión de lo que es América Latina y de su inserción en el mundo, y en consecuencia a teorizar sobre las relaciones internacionales latinoamericanas. ${ }^{2}$ Al respecto, parece necesario continuar con una propuesta que tiene ya décadas de desarrollo, y que consiste en la creación de elementos para una teorización propia, sobre este particular, Raúl Prebisch ya alertó sobre la no universalidad de las teorías de las relaciones internacionales que han sido productos del capitalismo, como lo registra Bernal-Meza en su libro sobre el pensamiento latinoamericano en relaciones internacionales. ${ }^{3}$ Roberto Russell, luego de una investigación de su grupo de trabajo - lo apunta también Bernal-Meza -, sostiene que en América Latina los autores de los escasos intentos por elaborar una teoría propia de las relaciones internacionales han sido abogados o diplomáticos; esto nos da lugar a reclamar también que se atiendan las aproximaciones de los historiadores en esa tarea.

Nuestro propósito, en esta ocasión es, en primer lugar, mostrar a los estudios de la historia de América como antecedentes de la historiografía de las relaciones internacionales latinoamericanas; luego, mencionar la evolución y desarrollo de algunas instituciones históricas e instituciones políticas vinculadas con estas relaciones.

1 En las elecciones de Argentina de 2007, que comprendían la presidencia de la nación, gobernaciones provinciales, intendencias y cargos parlamentarios, ha sido notoria la casi total falta de referencias a las ideas latinoamericanistas de concertación o integración en los discursos y plataformas de los candidatos.

2 En este sentido es oportuno recordar a Knutzen, cuando afirma que no hay que cuestionar si una teoría es verdadera o falsa, sino si es o no iluminadora. Ver KNUTZEN, Tornbjorn L. A History of International Relations Theory. Manchester University Press, 1997.

3 BERNAL-MEZA, Raúl. América Latina en el Mundo. El Pensamiento Latinoamericano y la Teoría de las Relaciones Internacionales. Buenos Aires: Grupo Editor Latinoamericano, 2005. 


\section{Los estudios de Historia de América como antecedentes de la historiografía de las relaciones internacionales latinoamericanas}

Hugo Biagini nos advierte que autores como Seignobos y Piaget, el primero a comienzos del siglo XX y el segundo a mediados de esa centuria, no incluían a la historia dentro de las ciencias sociales. ${ }^{4}$ ¿Será que por eso esta subalternidad en que era considerada la historia no la hacía merecedora de mayor papel en la elaboración de teorías de las relaciones internacionales? Nos parece evidente que la disciplina de las relaciones internacionales, en general, no reconoce debidamente el tributo que debe a la historia, en tanto que privilegia los aspectos del derecho, de la diplomacia, de los análisis de estrategia, de la economía, y sobre todo de la ciencia política aplicada a los Estados nacionales.

Como es evidente, algunas historias generales de América se aproximan a historias de las relaciones internacionales, en cuanto apuntan a una visión multilateral que supera la perspectiva polarizada de las historias que desde cada nación tratan las relaciones de su propio país. Una revisión de ciertos momentos en la aparición y desarrollo de historias de América que resultan antecedentes de la historia de las relaciones latinoamericanas muestra discontinuidades y grandes vacíos.

En América Latina, la primera Historia de América fue la escrita por el chileno Diego Barros Arana, pero sólo fue la reunión de las historias nacionales del continente, sin procurar un análisis valorativo de las cuestiones comunes ni una comparación que condujera a una mirada abarcativa del conjunto. ${ }^{5}$ Unos años antes otro chileno, Francisco Bilbao, había predicado en tono romántico desde la admirada París la creación de una Universidad Americana que reuniera - decía - "la historia del continente". Debe advertirse que los estudios históricos no estaban por entonces suficientemente desarrollados para acometer esa tarea, lo que hace del libro de Barros Arana un esfuerzo pionero en el camino para superar esa visión de conjunto. Un avance interesante por recorrer ese camino fue el libro del brasileño Rocha Pombo, ya al despuntar el siglo $X X$, como resultado de un concurso convocado por la iniciativa de Manoel Bonfim, precisamente un político e intelectual dedicado a las relaciones interamericanas y que sostuvo la pertinencia de

4 BIAGINI, Hugo. Historia y Ciencias Sociales. Todo es Historia. 236, Buenos Aires, enero de 1987.

5 BARROS ARANA, Diego. Historia de América. Buenos Aires: Ed. Futuro, 1862. 
llamar América Latina a esta parte del mundo. ${ }^{6}$ En este libro Pombo sostuvo que existía una historia común que debía conducir a elaborar programas de integración y solidaridad.

Como es de suponer, las primeras visiones de la historia continental y de las relaciones interamericanas se produjeron en los Estados Unidos, desde mediados del siglo XIX, y a comienzos del siglo XX ya había cátedras de historia americana en universidades estadounidenses. Lewis Hanke nos informa que Danjel de León daba clases de relaciones interamericanas en la Universidad de Columbia en 1884, y que Bernard Moses impartía cursos de historia de América en la Universidad de California en 1885.7 Pero los estudios continentales que superaron una fraccionada perspectiva nacional alcanzaron un mayor rango en la Universidad de Berkeley, donde desde 1922 Herbert Bolton daba clases sobre lo que denominaba "La Grande América"; Bolton ya concebía desde la historia la existencia de un Hemisferio Occidental, término acuñado en Estados Unidos como un espacio en el que este país debía ocupar la posición dominante y ejemplarizadora. Decía Bolton - lo anota Hanke - que "cada historia local tendría un significado más claro al ser interpretada a la luz de las demás, y que mucho de lo escrito sobre cada historia nacional no era sino un hilo de una madeja mayor".

En tanto, los primeros en introducir la materia Historia de América como tema de estudio en las Universidades latinoamericanas fueron Perú y Brasil, en la década de los 1930', pero por entonces no se notaba en su tratamiento un destacado interés por incluir en ella las relaciones inter-latinoamericanas. ${ }^{8}$

6 POMBO, Rocha. Compendio de História da América. Rio de Janeiro: Laenmert e Co., 1900. Acotemos que Rocha Pombo recibió el premio asignado a la mejor obra, aunque fue el único que se postuló; recibió cumplidos elogios de Bonfim en su calidad de juez del concurso.

7 HANKE, Lewis. ¿Tienen las Américas una Historia Común? Crítica a la Teoría de H. E. Bolton. Anuario. Facultad de Humanidades y Educación. Tomo I. Caracas, 1964.

8 La Historia del Perú de Basadre - la primera edición es de 1939 - está entre las pioneras dentro de los estudios de una historia nacional con una amplia y prolija preocupación por las relaciones con otras naciones latinoamericanas. Esto debe contextualizarse no sólo en la clarividente perspectiva con que el autor encaró la obra sino también en una realidad acuciante de la historia de su país, historia profundamente inficionada por las relaciones con sus vecinos. BASADRE, Jorge. Historia de la República del Perú. Lima, Ed. Peruamérica, 1963 y siguientes. 
En cuanto a los estudios de la historias de las relaciones internacionales latinoamericanas propiamente dichas, ellas han estado condicionadas a las etapas de la propia realidad de su historia y de las cuestiones internacionales propias de la época en que fue producida esa historiografía. ${ }^{9}$ Si bien pueden reconocerse diversas etapas, puede afirmarse que durante el siglo XIX y al menos la mitad del XX las tendencias nacionalistas, aunque impregnadas también de un cierto pensamiento liberal, fueron absolutamente predominantes.

Puede comprobarse también con cierta facilidad que el origen de los estudios locales de la historia de las relaciones internacionales latinoamericanas obedece al mandato de defender causas nacionales, especialmente en cuestiones vecinales, predominantemente limítrofes. Esa historiografía es de las más ricas en su género a nivel mundial, pero es también evidente que esas historias no contribuyeron a crear condiciones de solidaridad e integración, y a veces de respeto y tolerancia vecinales, sino más bien a recelos, armamentismos pretendidamente defensivos pero frecuentemente agresivos $\mathrm{y}$, lo que es peor, a connivencias con las potencias que utilizaron los conflictos regionales para avanzar en sus planes de penetración y apropiación. Si bien la historiografía ha superado paulatinamente estos condicionamientos, al mismo compás en que los conflictos reales entre estas naciones se fueron resolviendo, aún no mucho tiempo atrás Juan Carlos Puig acertaba en exhortar a los internacionalistas latinoamericanos a "desideologizarse" en beneficio de una verdadera ciencia de las relaciones internacionales. ${ }^{10}$

Un hito en la inclusión del tema de las relaciones internacionales en las historias generales de América Latina se produjo

9 Un caso altamente demostrativo de lo afirmado es el libro de SILVA, Carlos Alberto. La Política Internacional de la Nación Argentina (Buenos Aires: Imprenta de la Cámara de Diputados, 1946), cuyo subtítulo aclara lo dicho: Absoluta identidad de su tradición y sus principios con los sustentados en el Acta de Chapultepec, la Declaración de México, la Declaración de las Naciones Unidas y la Carta del Atlántico. En efecto, el texto de esta obra de 991 páginas está adaptado para demostrar que desde la propia revolución de independencia argentina los ideales y principios sobre sus relaciones internacionales habían sido perfectamente coincidentes con los que inspiraban las declaraciones impuestas por las potencias vencedoras de la segunda guerra mundial. Como se recordará, Argentina había sido excluida como firmante del Acta de Chapultepec, con lo que quedaba marginada de la entente americana liderada por los Estados Unidos, y este libro fue encargado por el gobierno para fundamentar su solicitud de ingreso al grupo que consagraba la mencionada Acta.

10 Introducción. En: PUIG, Juan Carlos (Comp.). Políticas Exteriores Comparadas. Buenos Aires: Grupo Editor Latinoamericano, 1984. 
cuando pasaron a ocuparse con mayor atención de las cuestiones económicas, al considerar la incorporación de estas naciones a la economía mundial. Existe cierto consenso en que esa incorporación se produce en la segunda mitad del siglo XIX. Los autores contemporáneos destacan que es entonces cuando adquieren importancia las cuestiones internacionales, aunque para tiempos anteriores se hacen referencias puntuales y esporádicas. Como ejemplos de estas puestas de relieve de las relaciones internacionales a partir de los fenómenos económcos, y a solo título ilustrativo, pueden citarse las historias de Chaunu, Carmagnani, Cortés Conde, Halperín Donghi, Cardoso y Pérez Brignoli. ${ }^{11}$

A la incorporación de las relaciones internacionales en las historias generales de América a partir de las cuestiones económicas sucede la comprensión de las historias generales de América como fenómenos de inter-relación entre naciones y pueblos, y entonces se toma cuenta que las culturas no se circunscriben a ámbitos nacionales, sino que los desbordan vinculando entre sí a los espacios nacionales. De todos modos, las visiones nacionalistas persisten en creer en la existencia de culturas nacionales más o menos cerradas en sí mismas, como si las culturas pudieran quedar encerradas en los límites entre naciones, muchos de ellos puramente geodésicos. Esta visión se corresponde con el predominio de las historias nacionales sobre las continentales, y en el mejor de los casos la subordinación de éstas a las primeras en la formación de la conciencia histórica de nuestras sociedades nacionales. La combinación de los conceptos de cultura y de nación, que elaboran los intelectuales - entre ellos los historiadores -, es una reducción que conduce a hacer cómplice a las culturas con los programas nacionales en política exterior. Esta creencia en la existencia de culturas nacionales en América Latina es otra de las dependencias de las interpretaciones de la historia de las naciones europeas.

La perspectiva de los historiadores de las naciones rectoras del orden mundial que se ocuparon de la historia de América Latina,

11 CHAUNU, P. Historia de América Latina. In: CARMAGNANI, Marcello. Estado y Sociedad en América Latina. 1850-1930. Barcelona: Ed. Crítica, 1984; CORTÉS CONDE, Roberto. Hispanoamérica. La Apertura al Comercio Mundial. 1850-1930. Buenos Aires: Paidós, 1974; HALPERÍN DONGHI, Tulio. Historia de América Latina. Buenos Aires: Paidós, 1972; CARDOSO, Ciro Flamarion S. y PÉREZ BRIGNOLI, Héctor. Historia Económica de América Latina. Barcelona: Crítica, 1984. Chaunu dedica un capítulo de su libro a las relaciones interamericanas, y Halperín Donghi enfatiza sobre un nuevo orden comercial producido por los intercambios internacionales. 
se ha presentado tópicamente, por lo general, como totalmente despegada de sus relaciones internacionales, como si ellas no existieran o como si fuesen un apéndice inerte que pendía de ese orden mundial sin orientación propia. Es interesante rastrear al respecto la primera de las series institucionales que se ocupan de esta región, esto es la Sociedad de Americanistas creada en Francia, la cual convocó en 1874 el Primer Congreso de Americanistas, que se realizó al año siguiente en Nancy. ${ }^{12}$ De los 1.500 participantes, sólo 186 eran americanos, o sea que se trataba de una reunión mayoritariamente de europeos estudiando América. Fue una típica asamblea del "imperialismo científico", con presencia de reyes y solemnidades palaciegas, impregnada de un sentido de curiosidad por interpretar un mundo exótico. En cuanto a los trabajos presentados, la mayoría se refería a la naturaleza americana y a sus habitantes originarios, sin hacer mayor diferencia entre ambos, es decir entre naturaleza y habitantes. El segundo Congreso se hizo dos años después, en Luxemburgo, y no fue muy diferente del primero. ${ }^{13}$ El tercero fue en Bruselas, en 1879, y siguió el mismo curso, inspirado sobre todo por los naturalistas franceses que lograban convocar a sus pares europeos para estudiar las rarezas americanas. ${ }^{14}$ Por fin, el cuarto se hizo en Madrid y, aunque predominaron los trabajos de españoles, la temática no cambió: se discutió sobre si Cuba estuvo o no pegada al continente, sobre la existencia de la Atlántida, sobre los mitos indígenas, y cosas por el estilo. América seguía sin tener historia, mucho menos relaciones internacionales propias. ${ }^{15}$

Los Congresos de Americanistas siguieron haciéndose en Europa - que era donde se estudiaba a América como un todo -, y sólo el undécimo se hizo en un país americano, México, en 1895; hasta que en el 1900 se dispuso la alternativa regular de un continente a otro. Como ha señalado Juan Comas, los estudios presentados a estos Congresos de la primera etapa traslucían un conocimiento científico de tono romántico y hasta fantástico. ${ }^{16}$

12 Congrés International des Americanistes. Compte-Rendu de la Première Session. Nancy1875. Nancy: G. Grèpin-Lebland, 1875.

13 Congrés International des Americanistas. Compte-Rendu de la Seconde Session. Luxembourg, 1877. Nancy: Victor Buck, 1878.

14 Congrés International des Americanistes. Compte-Rendu de la Troisième Session. Bruxelles1879. Bruxelles: Ed. Européenne C. Muquardt, 1879.

15 Congreso Internacional de Americanistas. Actas de la Cuarta Reunión. Madrid-1881. Madrid: Impr. de Fortanet, 1882.

16 COMAS, Juan. Los Congresos Internacionales de Americanistas. Sintesis Histórica éndice Bibliográfico General. 1875-1952. México: Instituto Indigenista Interamericano, 1954. 
Hubo una disputa para que la primera sede americana fuese en los Estados Unidos, pero su desestimación marcó que ésta era una invención europea con la mirada puesta en América Latina, y triunfó la posición que soslayaba el protagonismo norteamericano. En rigor, era esta puja una traslación al campo académico de la oposición entre el europeísmo y la réplica de los Estados Unidos, el panamericanismo, que entonces se abría paso y se consagraba institucionalmente con la primera Conferencia Interamericana, en 1889. Por esos tiempos, en Europa se consideraba al continente americano como una realidad opuesta a la civilización; apareció, entre otras, la idea de la tropicalidad, una naturaleza en la que se enseñoreaban las epidemias y la barbarie, en una combinación que hacían imposibles las formas civilizadas de vida. ${ }^{17}$ Se consideraba que estas condiciones influían en la laxitud física, que se prolongaban a una laxitud moral. Tan grave y falsa es considerar esta fatalidad climática como la de creer que toda América Latina es tropical, cuando tiene los climas más variados del planeta, en virtud de su naturaleza longitudinal, que se extiende de un polo a otro. Este concepto se refería con exclusividad al abordaje del estudio de las relaciones entre Europa y América Latina, ya que los Estados Unidos se desprendieron muy pronto del estigma.

Esta orientación persistente de los estudios era proporcional a la insuficiencia y hasta indiferencia con respecto a la extensión e intensidad de los estudios integrados de las relaciones internacionales latinoamericanas. Ha dicho Johan Galtung que el colonialismo científico se manifiesta cuando el centro de gravedad del conocimiento de una nación está fuera de ella. ${ }^{18}$

Es también interesante e ilustrativo observar las sedes de las Conferencias Interamericanas o Panamericanas iniciadas en Washington en 1889, y en ellas el tratamiento de cuestiones históricas y culturales. Contemplemos imaginariamente el mapa de América y ubiquémonos en Washington y en aquel año para luego dirigir la mirada hacia la sede del segundo de esos Congresos, en México, y luego bajando la vista hacia el sur contemplando el tercero, en Rio de Janeiro, para seguir descendiendo al cuarto, en Buenos Aires, y al quinto, con un viraje hacia el oeste, en Santiago de Chile, y de allí ascendiendo nuevamente

17 ARNOLD, David. La Naturaleza como Problema Histórico. El Medio, la Cultura y la Expansión de Europa. México: Fondo de Cultura Económica, 2000.

18 Cit. por MORNER, Magnus. El Estudio Actual de la Historia Latinoamericana. Semestre Histórico. 1. Caracas, junio de 1975. 
para ver la sede del sexto, en La Habana (en la cual se crea el Instituto Panamericano de Geografía e Historia, en 1928), para seguir ahora un movimiento circular hacia los sucesivos en Lima, Montevideo (en la que se crea el Instituto para la Enseñanza de la Historia, en 1933), Bogotá (donde se crea la Organización de los Estados Americanos, en 1948, con cierta atención sobre las cuestiones históricas y culturales), Caracas y Quito. ${ }^{19}$

Una línea trazada siguiendo cronológicamente este itinerario nos marca sugestivamente la marcha desde los Estados Unidos hasta el extremo sur del continente y entonces un movimiento circular y envolvente. Este trazado coincide geográfica y geométricamente con el proceso de penetración y hegemonía de los Estados Unidos. De poco valió que en aquella primera Conferencia la delegación argentina, con Roque Sáenz Peña a la cabeza, renegara de la doctrina panamericanista, y que en la tercera, de Rio de Janeiro, el delegado local Manuel de Oliveira Lima hiciera la propio, en este caso con el añadido de que personajes gravitantes en la política exterior brasileña como Joaquim Nabuco y el Barón de Rio Branco se inclinaron a contemporizar con Estados Unidos.

Como colofón, puede recordarse también la reunión de Presidentes Americanos de 1957 convocada por los Estados Unidos, y que se realizó en Panamá, usando, o más bien malversando, la casa donde se realizara en 1826 el Congreso convocado por Simón Bolívar. En 1826 la motivación principal era formar un cuerpo sólido de resistencia común contra los propósitos europeos de restablecer el dominio español; en tanto, en 1957 la reunión obedeció a una principal motivación: la de imponer la Doctrina de la Seguridad Nacional, a través de la cual Estados Unidos ejercía un control militar sobre las naciones latinoamericanas. Son hitos, momentos, acontecimientos, que la historia recoge y pone al servicio de interpretación de los internacionalistas, en la confianza de que sabrán usarlos para un mejor conocimiento y explicación de los fenómenos que estudian.

Como se ve, Europa y Estados Unidos observaban a América Latina según sus propios intereses y motivaciones. Mientras muchos latinoamericanos asumían la idea europea, otros se encolumnaban con Estados Unidos, en tanto otros más intentaban tener una opinión propia de sí mismos.

19 CAICEDO CASTILlO, José Joaquín. El Panamericanismo. Buenos Aires: Ed. De Palma, 1961. 
$Y$ en esta reseña histórica de reuniones e instituciones que constituyen hitos referenciales en el estudio de la historia de las relaciones internacionales no podemos dejar de mencionar las Jornadas que desde hace unos tres lustros se realizan en este Cono Sur, y que han tenido lugar en Argentina, Chile, Bolivia y Brasil. La primera de ellas, en Córdoba, se convocó bajo el lema de Teorías y Temas, marcando así el compromiso de pensar en la vinculación entre la realidad latinoamericana y la teoría con que debía abordarse su estudio; la aceptación fue tan favorable que las Segundas Jornadas, en Rosario, mantuvieron esa misma propuesta. Una sugerencia a jóvenes investigadores de esta materia, digna de una tesis para la culminación de sus estudios, puede ser la de analizar y exponer el desarrollo y evolución de estas sucesivas e ininterrumpidas Jornadas, señalando los resultados obtenidos y, en fin, mostrando los aportes y los contenidos de este movimiento intelectual que está, felizmente, muy vivo.

\section{Concepciones históricas de las relaciones internacionales latinoamericanas}

Las investigaciones sobre la historia de las relaciones internacionales latinoamericanas han creado algunos paradigmas que pueden considerarse claves para una interpretación propia de la materia.

Una de las perspectivas que implica uno de esos paradigmas la provee la observación de la dimensión espacial. Partiendo de la condición física de la totalidad del continente americano, características tales como una masa continental que va de un polo a otro polo; de un gran océano a otro gran océano; que divide o une otros continentes; que presenta ensanchamientos y angostamientos extremos; que se conforma como una combinación de regiones costeras, montañosas y selváticas; que, en términos de altitud, presenta sectores calurosos en las costas y en las tierras bajas, y a muy escasa distancia, en las altas montañas depara los fríos más intensos; que, de sur a norte, tiene climas fríos, templados, tropicales, ecuatoriales y nuevamente tropicales y templados, en extremo secos o lluviosos; que determinan regiones con cuatro estaciones climáticas, o con dos, o con sólo una y permanente, todo ello constituye un conjunto de condicionantes naturales que tiene una incidencia singular en las relaciones entre naciones $y$ comunidades, distintas y únicas a las de cualquier otra gran región del planeta. 
Incluso una visión de las relaciones internacionales desde el estricto campo de la política es evidente la vinculación del espacio con las políticas exteriores de las naciones, en las que se concibe a los espacios como territorios, esto es como la superficie geográfica que contiene a la nación. Taylor ha dicho que "el nacionalismo suele ser considerado el más geográfico de los movimientos políticos" ${ }^{20}$ Es claro que esta definición da lugar a diferentes actitudes políticas frente al espacio considerado como territorio, en un abanico que va desde las especulaciones geopolíticas que trazan hipótesis de conflicto y enfrentamiento hasta las que, en el otro extremo, trabajan hacia fuera de la integración, a partir de hipótesis de cooperación.

Debe tenerse siempre presente en este diálogo del hombre con la naturaleza el papel que juegan los elementos naturales: una cadena montañosa que atraviesa la mayor parte de su extensión longitudinal y que por tanto presenta todos los climas y depara al hombre un hábitat a diferentes altitudes, todo lo cual genera los más diversos tipos de vida comunitaria; el de una selva que ocupa gran parte de su masa continental y que ofrece desafíos para su traspaso y circulación, además de ser compartida por varias naciones; la enorme masa montañosa, aún con la numerosa variedad de formas de vida que depara, sirve de vertebración natural para fundamentar una organización supra-nacional, como lo es la Comunidad Andina de Naciones; hay también ríos que forman cuencas internacionales, que atraviesan regiones y naciones y que comunican naturalmente a países, comunidades, regiones y naciones; extensos e inhóspitos desiertos, por su parte, constituyen desafíos que el hombre debe enfrentar con sentido comunitario para su ocupación y supervivencia. Todos estos elementos operan de manera complementaria y yuxtapuesta; piénsese, por ejemplo, que la selva y la cuenca amazónicas reciben el indispensable tributo de los caudalosos ríos cordilleranos, quedando así el sistema montaña-río involucrado en la mayor parte de las naciones sudamericanas. Todos estos elementos y fenómenos son fundamentales para comprender la peculiaridad del espacio latinoamericano, espacio que informa y condiciona las relaciones entre sus naciones y de su conjunto hacia el exterior, y cuya especificidad no se asemeja a la de ninguna otra parte del mundo.

20 TAYLOR, Peter J. Geografía Política. Economía Mundo. Estado-nación y Localidad. Madrid: Trama Ed., 1994. 
Otro paradigma es el que podemos denominar patrones culturales. Sucesivas camadas de población, con una numerosa variedad de grupos étnicos, originarios de este continente o provenientes de otros continentes, su superposición, miscegenación e hibridación, a su vez consistentes en procesos de ocupación, de dominación, de sometimiento de unos grupos sobre otros, provee unas características igualmente singulares, no repetidas en ninguna otra parte del planeta.

Un tercer paradigma es el de las regiones de frontera. Es importante al respecto el aporte de Hebe Clementi en su estudio de la frontera en América Latina. Dice ella que las fronteras son factores de integración y constituyen espacios de interacción, y concluye expresando: "Cómo esas tierras desiertas, o casi desiertas, devienen fronteras, es la historia de América en su sentido más pleno". ${ }^{21}$ Por extensión, podemos agregar que las fronteras son una clave fundamental para entender las relaciones internacionales latinoamericanas. Es pertinente formular una caracterización de esas regiones de frontera en un dimensión temporal, esto es a través de las sucesivas etapas históricas, a partir de su condición de espacios excéntricos al sistema de dominación en la época colonial, y por tanto abandonados o relegados, para ser después de las independencias zonas de conflictos entre los Estados nacionales en su vocación de afirmar soberanías sobre bases territoriales, y en la actualidad espacios de desarrollo más o menos espontáneo, a menudo desordenado y voluntarista, en razón del desinterés oficial, generalmente concentrado en la explotación de recursos naturales y en asegurar soberanías territoriales. Esta periodificación puede continuar en el futuro convirtiendo a estas regiones de frontera en regiones de concertación y convivencia propicias para potenciar el proceso de integración.

Un valioso ejemplo de estudio sobre el tema, que escogemos no sólo por su cercanía sino también por la rigurosidad de su planteamiento, es el de Leonardo León y Sergio Villalobos, que identifican tipos humanos en la frontera araucana de Chile y Argentina de fines del siglo XIX. ${ }^{22}$ Se trataba de individuos

21 CLEMENTI, Hebe. La Frontera en América. Una Clave Interpretativa de la Historia Americana. Tomo I. Buenos Aires: Leviatán, 1985.

22 LEÓN, Leonardo y VILLALOBOS, Sergio. Tipos Humanos y Espacios de Sociabilidad en la Frontera Mapuche de Argentina y Chile, 1890-1900. Propuesta de Investigación. Estudios Historiográficos. Universidad de Valparaíso. I, 1. Valparaíso, segundo semestre de 2002. 
profundamente caracterizados por su pertenencia a un espacio marginal y fronterizo, tanto que los autores afirman que no eran reconocibles como chilenos ni como argentinos y ni tan siquiera como mapuches, eran simplemente fronterizos; he aquí, entonces, otro tipo humano en el Cono Sur, el fronterizo, que se suma a los protagonistas de las relaciones vecinales latinoamericanas, y que podemos encontrar en cada una de la fronteras que separan a sus naciones.

Un cuarto paradigma es el de la nacionalización de las culturas. En efecto, una labor recurrente de los gobiernos nacionales ha sido la de nacionalizar espacios regionales, es decir que dada la existencia de una región por un proceso distinto del nacional, se ha procurado dar a una región el carácter de nacional, con el recurso de la "ciudadanización" de sus poblaciones, con frecuencia comunidades indígenas ajenas a sentimientos nacionales; el estudio de Pilar García Jordán para espacios amazónicos, en el que muestra la tarea de cooptación de misiones jesuíticas por gobiernos nacionales con el fin de peruanizar, ecuatorianizar o bolivianizar sectores de la región amazónica, es ilustrativo al respecto. ${ }^{23}$ Estos esfuerzos estatales, sin embargo, no han logrado suprimir la identidad "amazónica" de sus habitantes, a menudo más fuerte y más profunda que su propia identidad nacional.

Es notorio que el mapa político de América Latina, que registra los límites de sus naciones, no coincide en absoluto con un mapaaún por hacer - que registre sus componentes étnicos o culturales, mapa de suyo complejo y difuso. Por el contrario, la identidad lingüística es mucho más simple y generalizada que las divisiones nacionales. Penetrar en el análisis de estas características que se complementan, se yuxtaponen, se oponen o combinan, conduce a conformar un cuadro de especial complejidad y de riqueza de elementos y a elaborar interpretaciones que se vinculan directamente con la especificidad de las relaciones entre las naciones latinoamericanas.

Parece también necesario ahondar el estudio de la incidencia en las relaciones internacionales de ciertos aspectos de la formación de los Estados nacionales, en que las disputas regionales son factores incidentales o decisivos en la creación de naciones; el caso más

23 GARCÍA JORDÁN, Pilar. Misiones, Fronteras y Nacionalización en la Amazonía Andina (Perú, Ecuador y Bolivia). Siglos XIX-XX. En: GARCÍA JORDÁN, P. y SALA Y VILA, Núria (Comp.). La Nacionalización de la Amazonía. Barcelona: Universitat de Barcelona, 1998. 
evidente es el de la República del Uruguay, que nace dentro del conflicto que enfrenta al Brasil y a Argentina, y también el de Ecuador, disputado entre el Perú y la Gran Colombia. Esta realidad permite hablar de naciones de frontera o de naciones intermediarias, en cuanto a sus orígenes, esto es unas anchas fronteras históricas que alcanzan la categoría de nación en un proceso impulsado por rivalidades regionales, y que exceden la condición de cuestiones bilaterales para alcanzar la dimensión de cuestiones multilaterales.

Las regiones internacionales constituyen otra de las características que inducen a considerar la dimensión espacial en las relaciones internacionales. Estudios tales como el de Beatriz Figallo para el Chaco paraguayo, argentino y brasileño, con motivo de la guerra del Chaco, que genera relaciones trilaterales ${ }^{24}$, y de Graciela Sturm, que analiza la explotación de la yerba mate desde la perspectiva de una explotación de características internacionales en la confluencia de Argentina, Paraguay y Brasil, constituyendo una verdadera región de frontera a partir de la explotación de un producto $^{25}$, ilustran sobre la incidencia que tienen las estructuras regionales en la evolución de las relaciones entre naciones. Por su parte, Delia Otero ha demostrado los entrecruzamientos entre las relaciones internacionales e inter-regionales en la zona comprensiva de territorios del sur del Brasil, Mesopotamia argentina y uruguaya y gran parte de la gobernación española de Asunción, donde se dio un fuerte multiculturalismo. ${ }^{26}$

Pero de la experiencia histórica hay que pasar también a la prospectiva hacia el siglo XXI, porque ya se insinúa la formación de regiones subterráneas, como ocurre con el Acuífero Guaraní, que está debajo de las superficies territoriales de parte de Argentina, Brasil, Uruguay y Paraguay y constituye el tercer reservorio de agua en el mundo. ${ }^{27}$ Anotemos que en 1997 los cuatro países firmaron el Acta de Paysandú, comprometiéndose a coordinar

24 FIGALLO, Beatriz. Espacios Nacionales y Espacios Regionales. Conflictos y Concertaciones en las Fronteras Chaqueñas de Argentina, Bolivia y Paraguay. Anuario de Estudios Americanos. Escuela de Estudios Hispano-Americanos. LX, 1. Sevilla, enero-junio de 2003.

25 STURM, Graciela. Yerba Buena y Yerba Mala. Medio Siglo de Producción y Trabajo en los Yerbales Misioneros (1890-1942). Buenos Aires: Universidad de Buenos Aires, 2006.

26 OTERO, Delia. Articulación Estado-Región de Frontera en el Área de Misiones o Palmas. Cuadernos de Historia. Serie Economía y Sociedad. Área Historia del CIFFyH. 5. Córdoba, 2002.

27 LATORRACA, Martín y MARTíNEZ, Maximiliano. Sistema Acuífero Guaraní. La Sed de Apropiarse del Agua. Le Monde Diplomatique "el Dipló". VII, 74. Buenos Aires, agosto de 2005 . 
investigaciones y a concertar el desarrollo sustentable del Acuífero. Como se ve, estamos ya ante la existencia de una Región Subterránea, una nueva categoría espacial en las relaciones internacionales latinoamericanas, que ha originado un acuerdo con vistas al futuro; a propósito, es bueno recordar que la UNESCO prevé para el 2025 que unos tres mil quinientos millones de personas padecerán escasez de agua. Las demandas hacia una equitativa distribución del agua potable hace que los yacimientos de agua, incontaminados, vengan a subsidiar y a reemplazar a los depósitos de la superficie, crecientemente contaminados. Estas realidades nos conducen a ir formando, desde la historia y hacia el futuro, mapas regionales que se superponen a los nacionales y que ocupan espacios internacionales, tanto superficiales como subterráneos.

La existencia de regiones internacionales, regiones de frontera, regiones culturales, regiones subterráneas, naciones intermediarias, nos conduce a asignar a la dimensión espacial un papel fundamental en la elaboración de una teoría para las relaciones internacionales latinoamericanas, íntimamente fundadas en procesos históricos en combinación con la naturaleza; reconocer la importancia de la dimensión histórica para comprender el presente, nos conduce a tender un fuerte hilo de conexión entre el pasado, el presente y el futuro de esta América Latina.

A su vez, el reconocimiento de la existencia de espacios como éstos, que se incorporan como partes dignas de consideración en las relaciones internacionales, nos lleva necesariamente a detectar cuál es el papel de las poblaciones en la conformación de las relaciones, y a establecer su protagonismo hasta reconocer su condición de actores de las relaciones internacionales. A su vez, con su desempeño cotidiano, estos actores son verdaderos agentes de creación de conceptos inherentes a las relaciones. En efecto, las teorías pueden ser la creación de una persona esclarecida, o de una escuela académica, pero son también el resultado de un proceso colectivo de intelección de la realidad, y de su consiguiente comprensión.

El reconocimiento y la caracterización de las regiones como espacios que participan activamente en las relaciones internacionales implica abrir hipótesis en los estudios concretos que reconozcan la existencia de relaciones inter-regionales superpuestas y recíprocamente incidentales con las relaciones internacionales propiamente dichas. En éstas, el papel del Estado se manifiesta por sus decisiones ostensibles; en las de carácter regional 
el papel cabe a las poblaciones, a las comunidades, que son las protagonistas anónimas de las relaciones. Este reconocimiento y caracterización de las regiones conduce necesariamente a descubrir e identificar a los actores que se destacan en esas regiones por tener un papel activo en esas relaciones, convirtiéndose así en agentes de las relaciones internacionales. Esto es, combinar en los estudios las relaciones estrictamente inter-nacionales - predominantemente estatales - con las relaciones inter-regionales, constituye una alternativa válida para enriquecer la comprensión de nuestra realidad pasada y presente.

Otro de los aportes de la historia a la formación de una concepción genuina de las relaciones internacionales latinoamericanas es la observación y explicación de los procesos de independencia de sus naciones. Partir del carácter internacional de las revoluciones, que deben explicarse necesaria y fundamentalmente en el contexto internacional de la época en que se consumaron, es uno de los puntos de partida para entender no sólo cada una de las revoluciones de los países latinoamericanos, sino también para su comprensión global e inter-vinculante. Terminar reconociendo que las independencias son aún un proceso en curso, constituye otra de las premisas de base en este aspecto; en ese sentido, es válida la expresión "segunda independencia", ya acuñada en medios intelectuales para la próxima conmemoración de los doscientos años de las revoluciones de emancipación de los naciones originadas en el tronco español.

También es necesario considerar que varias naciones no se independizaron de sus dominadores europeos, sino de sus vecinos, tales los casos de Uruguay, que se desliga de Argentina y de Brasil; de Bolivia, que se emancipa de Argentina y del Perú; del Paraguay, que se pronuncia contra la centralización de Buenos Aires; del Ecuador, que se desvincula de la Gran Colombia; de Panamá, que se separa de Colombia. Esta es otra de las claves interpretativas de las relaciones internacionales latinoamericanas, la de los procesos de independencia, que matiza y corrige la interpretación de las emancipaciones como excluyentes epopeyas liberadoras del yugo europeo.

Este siglo XXI parece convocar a los latinoamericanos a descubrir y afirmar su verdadera y auténtica identidad. La hora parece propicia en esta era de la globalización, que es también la de las recomposiciones de las estructuras del orden mundial. Al respecto, de los términos usados por Octavio Ianni para definir al 
mundo de la globalización el más interesante es el de nave espacial. ${ }^{28}$ En efecto, la idea de nave o de navegación implica la extrema movilidad del hombre en el planeta y también la inmediata repercusión de cada acontecimiento en el resto del mundo, eso sí que en menor o mayor grado según cómo esté involucrado cada país. Pero más interesante aún es la idea de espacio que, unida al de la navegación, nos señala la importancia de los lugares, de las regiones, de las ubicaciones relativas, especialmente en función de los desplazamientos, de las comunicaciones, de los intercambios y de las apropiaciones territoriales. América Latina, en efecto, ocupa un lugar singular en el planeta, y ello constituye un factor que las potencias advirtieron desde los primeros tiempos de la conquista, y en consonancia llevaron a cabo programas para asegurarse posiciones dominantes; posee, por lo demás, lugares o sitios estratégicos, también advertidos por las potencias, como que uno de los principales motivos de disputas imperiales fue por la ocupación de espacios claves para la economía y la estrategia de dominación. Se trata, para el autor brasileño, de un espacio caótico, tanto que los individuos tienen dificultades en comprender que están extraviados; es una especia de Torre de Babel. Pero precisamente su carácter caótico es el principal motivo para que América Latina tome conciencia de su lugar en el mundo y adquiera capacidad para desenvolverse y desarrollarse en este mundo caótico, condición necesaria para superar esa situación.

Este pensamiento es compatible con el del filósofo mexicano Abelardo Villegas, que afirmó que "el descrédito de las antiguas doctrinas abre la posibilidad de una creatividad, es decir que los pueblos y las personas inventen sus propias soluciones. No desde la nada, desde luego - decía - porque de la nada, nada sale, sino a partir de la experiencia histórica y recordando a cada paso que las ideologías dogmáticas son como cortinas de papel que ocultan la verdadera naturaleza de los hechos" ${ }^{29}$

En fin, cuando tengamos una interpretación propia de la realidad latinoamericana, lo que sólo se logrará cuando se elabore una teoría inspirada y basada en nuestra propia realidad histórica, se abandonarán las ideas acerca de similitudes con el resto del

28 IANNI, Octavio. Teorias da Globalizaçao. Rio de Janeiro: Civilização Brasileira, 2002.

29 VILLEGAS, Abelardo. Perspectiva de América Latina. Cuadernos Americanos. Nueva Época. XV, 6, 90. México, noviembre-diciembre de 2001. 
mundo, como base para una conceptualización, hasta reconocer definitivamente nuestras peculiaridades y originalidades.

\section{La regionalización en la historia de las relaciones internacionales latinoamericanas}

Otra cuestión sobre la cual es necesario reflexionar en esta materia es la de los procesos de regionalización en América Latina. Es evidente que las estrategias nacionales para el desarrollo de las relaciones internacionales de esta parte del continente lo han sido a partir de los aparatos de los Estados. Es necesario admitir que en la formación de las naciones latinoamericanas prevaleció la decisión de sectores prominentes de la sociedad más que la voluntad colectiva de los pueblos; no porque los pueblos carecieran de la vocación de la emancipación, sino más bien todo lo contrario; de lo que se desprende que si éstos hubieran prevalecido sobre las decisiones de aquellos grupos dirigentes, otra hubiera sido la distribución espacial de las naciones. En otras palabras, las naciones latinoamericanas se hicieron desde arriba hacia abajo, en tanto los pueblos pujaban por formar regiones que devinieran finalmente en naciones.

Esta comprobación lleva a una pregunta que provoca la puesta en discusión sobre si es acertado decir que antes de la organización de la consolidación de los Estados nacionales y de las formaciones nacionales, y de su consagración institucional y jurídica, puede hablarse de relaciones internacionales propiamente dichas, y más precisamente de los países latinoamericanos entre sí; y si no podemos llamarlas así, cómo debemos nombrar a las relaciones que hubo entre estos países. Otra evidencia es que hasta entonces hubo un orden o sistema colonial, seguido por un proceso de gestación y formación de los Estados nacionales, hasta llegar a la existencia de estos Estados; tener en cuenta estas condiciones implicaría que los estudios de estas relaciones se harían más sistemáticos, más ordenados, más factibles.

Admitir que aún antes de la consolidación de los Estados nacionales hubo relaciones, nos conduce necesariamente a considerar cuáles son las dimensiones espaciales desde las cuales se puede plantear un análisis de estas relaciones. La hipótesis es que antes de la existencia de las naciones organizadas desde un Estado hubo en América Latina espacios regionales; algunos más delimitados que otros; entre los primeros podemos mencionar, a manera de ejemplo, al Caribe, la Amazonía, el Altiplano Andino, 
la Cuenca Platense, el Altiplano Andino, el Mato Groso, el Plata, etc. Las denominaciones marcan el fuerte acento que se daba al escenario, a la geografía, al espacio territorial en sí. Estas unidades alcanzaron una específica característica que los particularizaba, y además una connotación con respecto a su entorno continental que las ubicaba en un contexto en el cual cumplían un rol y tenían una gravitación singular.

\section{El factor étnico en la historia de la regionalización y de las relaciones internacionales e inter-regionales latinoamericanas}

Expuesto así someramente el marco histórico y espacial, cabe formular algunas reflexiones sobre los conceptos teóricos desde los cuales puede alcanzar su contextura una comprensión cabal de la cuestión de la multi-culturalidad, considerada desde una perspectiva de la regionalización desde la cual pueden apreciarse las relaciones entre los países latinoamericanos. Como advertencia preliminar, corresponde aclarar que a fines instrumentales, y sin la pretensión de entrar en el arduo y no resuelto debate sobre los alcances y significados de los conceptos de cultura y de etnia, utilizamos ambos términos en cuando los dos se refieren a un conjunto de rasgos comunes de la vida social de un grupo humano que es posible identificar como tal, distinguiéndolo así de los demás, y cuyos miembros interactúan entre sí reconociéndose como herederos, portadores y curadores de un patrimonio histórico y cultural que les es propio y distintivo.

Por lo dicho hasta aquí, queda claro que la incorporación de los grupos étnicos como factores de las relaciones internacionales no implica solamente su caracterización a los fines de localizar su inserción en el conjunto de los actores; también supone la necesidad de introducirse en sus mecanismos internos estructurales, organizativos y funcionales, y el de considerarlos como instalados en un espacio que les es propio; a partir de esta comprensión, es preciso entender cuál puede ser su incidencia en la conformación de un sistema internacional.

La comprensión del concepto de multi-culturalidad - esto es de convivencia o contacto de grupos de diversas culturas en un mismo espacio regional, nacional o internacional - requiere la consideración de otros elementos que intervienen en los fenómenos sociales que lo involucran, y que obran en la realidad condicionando y caracterizando las formas con que se manifiesta. 
Uno de ellos es la creciente homogeneización, similitud o igualación cultural, resultado precisamente del encuentro y confluencia de grupos humanos de diversas nacionalidades y culturas que participan en común de un mundo globalizado, el que impone patrones comunes de vida cotidiana. Desde una perspectiva sociológica, ello adquiere su mayor sentido cuando se trata del fenómeno social de la masificación, que a su vez alcanza sus mayores dimensiones y sus formas más explícitas en los grandes conglomerados urbanos. Esto equivale a decir que la globalización obra compulsivamente sobre las culturas, imponiéndoles hábitos y conductas, y por tanto, alterando las formas de la cultura propia.

En el campo de las relaciones internacionales este fenómeno tiene un correlato en el de la globalización, que comprende no sólo las cuestiones que han convocado la mayor atención de los internacionalistas - esto es las económicas -, sino también las de naturaleza política y estratégica. Esta especie de mundo cosmopolita - aceptando este término sólo en su acepción de lo que es más o menos común a todos los países o a la mayoría de ellos - sería, así - en lo que se refiere a las cuestiones sociales y culturales -, lo que la globalización es para la economía, la política y la estrategia.

Sin embargo, parece que hasta aquí ha sido más común que este fenómeno sea visto como el resultado de procesos de yuxtaposición, absorción, mimetización o imitación cultural, todo lo cual conduciría a la universalización o igualación de las pautas, prácticas y modelos de la vida social. La sociedad globalizada, como resultado de esta suerte de cosmopolitismo, se dirigiría así hacia la formación de una cultura universal.

Ahora bien; la réplica a la globalización, que obra a la manera de rechazo a ésta y como una alternativa valiosa, se apoya en la existencia de diferencias regionales y en la necesidad de reconocer esas diferencias para evitar que las regiones ricas ahoguen o impidan el crecimiento de aquellas con menor capacidad competitiva para los intercambios materiales, lo que en América Latina constituye uno de los contrastes más impactantes. Ella postula el reconocimiento de las particularidades locales, regionales o nacionales y, al rescatar sus valores y al demandar su legitimación en la vida política, reclama no sólo respetarlas sino también protegerlas. 
Así como a la globalización se opone este tipo de regionalización cuando se trata de asuntos inherentes a la economía, a la política o a la estrategia, a la homogeneización o cosmopolitismo se opone el multi-culturalismo cuando se trata de cuestiones culturales y étnicas. ${ }^{30}$ Desde esta perspectiva, globalización y cosmopolitismo serían dos términos homólogos, en tanto el uno representa en las estructuras de poder político lo que el segundo significa en lo social y cultural. Lo mismo podría decirse de los términos regionalización - tal como lo hemos caracterizado - y multi-culturalismo, por cuanto el primero propone la consideración de las diferencias regionales en las estrategias político-económicas y el segundo alienta la legitimidad y protección de las diferencias étnicas y culturales.

En rigor, y ya en una primera observación, el fenómeno de la multi-culturalidad es el que aparece más extendido en la realidad mundial de la actualidad. Como resulta evidente, ello se debe a los acontecimientos históricos de este siglo que han hecho del planeta una real ecúmene, a la mayor movilidad social, al incremento de las migraciones, al impresionante desarrollo de la tecnología, a la curiosidad por extender el conocimiento de los espacios del planeta, y a otros factores concomitantes; entre ellos es pertinente agregar un creciente respeto por el otro en algunas comunidades.

En este contexto, los esfuerzos de los Estados por afianzar una supuesta cultura nacional han conspirado contra la integración entendiendo como tal una armónica y equitativa reunión de las partes -, al intentar desvanecer los matices que son comunes en las formas culturales presentes en otras naciones, para poner más en evidencia las diferencias que distinguen a una nación del resto, en especial de las vecinas. Esta actitud de diferenciación se expresa también en el afán de los sectores dirigentes de fomentar la introducción de formas de la civilización europea, a la que admiran, lo que se origina tanto en el deseo de imitarla y parecerse a ella, como de acentuar sus diferencias con respecto a sus pares latinoamericanas.

Esta cultura nacional así entendida, como producto de la acción de los aparatos del Estado, tiene también la misión de revelar y ostentar una identidad nacional que consolide a la nación como

30 El término "multi-culturalismo" se refiere a la posición adoptada en defensa de la legitimidad de la pluralidad cultural, en tanto que "multi-culturalidad" alude al fenómeno de la pluri-culturalidad en sí mismo, y por tanto es un concepto neutro. 
una entidad distinta en el orden internacional. Por el contrario, esta identidad debiera ser buscada a partir del otro extremo, esto es desde la interioridad de cada uno de los individuos que se reconocen a sí mismos como parte de un grupo social y cultural.

A la vista de la persistencia de este multi-culturalismo que se presenta como opuesto a proyectos homogeneizadores de los Estados nacionales o del ordenamiento social predominante, cabría hablar de culturas regionales antes que de culturas nacionales; estas regiones caracterizadas por su cultura pueden corresponder a un espacio geográfico comprensivo de más de una nación, o de partes de más de una nación, y así tendríamos un espacio dotado de un determinado grado de mono-culturalidad, que a su vez es un espacio perteneciente a más de una nación. He aquí la conjunción que estábamos buscando desde el comienzo de estas reflexiones, la que vincula al espacio con el hombre, a la región con la cultura.

Aun cuando en las estrategias diplomáticas y políticas de los Estados estas sociedades suelen ser vistas como causa de fragmentación y debilitamiento de la cohesión nacional, por ser ajenas o refractarias al modelo impuesto, estas regiones culturales pluri-nacionales podrían ser observadas desde otra perspectiva, y sobre todo en un sentido prospectivo, en su condición de factores de soldadura y cohesión internacional en América Latina.

Todo esto implica que el multi-culturalismo, en América Latina, no se refiere sólo a la convivencia de culturas, sino también a la fusión de culturas. La generalidad de los países latinoamericanos ha experimentado este proceso de mestizaje; sólo ha habido diferencias de grado, no de sustancia. Este es un denominador común que suministra una base importante para dar sentido y consistencia a una mirada común sobre la vasta región, y que debe estar presente de manera permanente en todas las consideraciones sobre la incidencia de la multi-culturalidad en la red de relaciones internacionales latinoamericanas.

En la detección y comprensión de los factores que inciden en esta problemática debe tenerse muy en cuenta un ingrediente fundamental, cual es el de que la historia del mestizaje (tanto el biológico como el eminentemente cultural, adquirido sobre todo en la educación, tanto formal como informal) registra el uso de la compulsión, de la violencia física o simbólica, de la aversión y, en fin, de diversas formas de coacción; aún es necesario hacer un sondeo en las mentalidades colectivas e individuales para detectar las marcas que ese violento proceso produjo. Podría extenderse a 
nuestro ámbito la afirmación que Arnold Senbv ha formulado observando las cuestiones étnicas en un país africano, en cuanto a que "la definición del término mestizo, la terminología que de ella se deriva y su utilización en la vida diaria no han tenido su origen en causas impuestas por sucesivos regímenes nacidos de las sucesivas oleadas de agresiones, penetración y asentamiento en Sudáfrica de las naciones burguesas de Europa, en sus fases comercial e imperialista...". ${ }^{31}$

En fin: ¿Cómo debe dividir, caracterizar y clasificar el espacio un cientista social que intenta explicar los mecanismos de las relaciones entre los países de América Latina, y que parte del supuesto de la existencia de una intensa diversidad cultural? ¿Por sus regiones, por sus naciones, por alguna otra categoría espacial, social, política? ¿Y si lo es por las regiones, cuál es la incidencia del factor cultural en la conformación regional y qué derivaciones tiene ello en las relaciones internacionales? He ahí la cuestión.

Por último, el estudio de la multi-culturalidad, de la homogeneización o cosmopolitismo, del etno-centrismo y otras categorías analíticas vinculadas a la existencia y coexistencia nacional e internacional de diversas culturas y etnias, debe ser planteado en relación estrecha con la condición política y legal del extranjero en América Latina; en última instancia, esto es lo que hace vinculante la concepción de las relaciones internacionales desde la perspectiva política y diplomática, con esta otra, que postula la incorporación de la dimensión social y cultural en la contextura y trama de esas relaciones internacionales.

En fin, la incorporación de los grupos étnicos y con ella una reconsideración de la dimensión espacial en el desarrollo de las relaciones internacionales, nos hace presumir que los esfuerzos teóricos deben estar encaminados a considerar que ellas involucran también relaciones inter-étnicas y relaciones inter-regionales; en ocasiones alguna de estas categorías puede resultar más expresiva de la realidad que las relaciones que se dan estrictamente entre las naciones como tales, a partir de sus actores ostensiblemente reconocidos como predominantes hasta aquí, esto es los Estados. Resulta obvio que en tanto se midan las relaciones internacionales en lo que Ray Cline denominó el poder perceptible, y a éste se lo

31 Cit. por WALLERSTEIN, Imanuel. La Construcción de los Pueblos: Racismo, Nacionalismo, Etnicidad. En: WALLERSTEIN, I. y BALIBAR, Etienne. Raza, Nación y Clase. Madrid: Iepala, 1991. 
cuantifique por factores tales como la cantidad de población, el tamaño del territorio, la capacidad económica, los objetivos estratégicos y, sobre todo, el poderío militar, esta incorporación y esta reconsideración serán difíciles de lograr. ${ }^{32}$

Es claro que para ese avance habría que renunciar a considerar a las relaciones internacionales como estrictas pujas por prevalecer - en el caso de las naciones latinoamericanas, apenas a participar en el orden mundial con el uso del poder material, y en cambio entenderlas como el conjunto de todas aquellas acciones que los hombres y los pueblos realizan en relación con otros y en su movilidad en el planeta para alcanzar la plenitud de su realización integral en sistemas que reconozcan, como uno de sus principios más caros, los derechos de todos a ejercitar y sostener las peculiaridades culturales de cada una de las diversas comunidades que habitan el planeta.

\section{Pautas metodológicas para incorporar el factor étnico en el estudio de la historia de las relaciones internacionales}

Derivados de esta propuesta de incorporación de los factores étnicos en el estudio de la historia de las relaciones internacionales, considerándolos en su ubicación en un habitat determinado que constituye su espacio regional, aparecen algunos principios metodológicos, indispensables para que la observación logre esa inserción.

Para resolver las cuestiones planteadas debe tenerse muy en cuenta la interdependencia e interacción de los conceptos de etnia y de nación. El factor étnico, obviamente, se presenta así como uno de los criterios tipológicos, y uno de los más significativos, para determinar la condición de extranjero; muy probablemente se observará que una misma etnia es pasible de ser considerada en diferentes grados de extranjería, según sean los tiempos y lugares considerados. Etnias estimadas como "extranjeras" habrán dejado de serlo en determinados momentos del devenir histórico, o etnias "nacionales" habrán pasado a la incómoda categorización de extrañas, según sean las circunstancias. En fin, el concepto de extranjero debe ser observado como un producto histórico, y por tanto dotado de una dosis de mutabilidad.

32 Ray Cline puede ser considerado, por estas ideas, partidario de un realismo extremo. Una versión latinoamericana de su teoría es asumida por ME.LO, Leonel Itaussu Almeida. Argentina e Brasil. A Balança de Poder no Cone Sul. São Paulo: Anablume, 1996. 
Parece conveniente tener en cuenta las distintas etapas de la vida política de las naciones, que en América Latina presenta antecedentes confederativos, integrativos, centralizadores, como así también problemáticas regionales e inter-regionales, cuestiones limítrofes y fronterizas, apropiación y explotación de espacios vacíos, semi-vacíos o vaciados de sus habitantes naturales, redes y barreras en las vías de comunicación altamente condicionantes de las relaciones, hondos procesos ideológicos de afirmación de nacionalidades, luchas civiles originadoras de estados civiles especiales como el asilo, el exilio, el desarraigo, el extrañamiento, el ostracismo, etc. Cada una de estas problemáticas pretéritas y presentes conduce a la necesidad de tener en cuenta el elemento étnico, hasta llegar a reconocer las cuestiones étnicas como un factor y a los grupos étnicos como actores en la historia de las relaciones internacionales latinoamericanas.

Todo ello forma parte de un complejo proceso dentro del cual se ubica la condición de nacional y de extranjero en los países latinoamericanos, y demuestra la existencia de gamas infinitas que van de lo que es un ciudadano "nacional" a un ciudadano "extranjero". La consideración de los desfases, desequilibrios y contradicciones que se han producido entre las regiones culturales y los espacios nacionales, con todas sus implicaciones sociales, políticas y estratégicas, puede contribuir a un mayor esclarecimiento de la naturaleza de los conflictos vinculados con el tema.

Estos planteos imponen a su vez meditar detenidamente sobre las fuentes a consultar. En rigor, los documentos para la historia de las relaciones internacionales han sido utilizados, por lo general, para conocer las tratativas diplomáticas, las políticas exteriores o las normas jurídicas. Parece probable que esas mismas fuentes puedan depararnos otras informaciones que nos acercarán al conocimiento de las mentalidades - tanto colectivas como individuales -, a los mecanismos de los discursos persuasivos, a las ideologías, y hasta a las formas del inconsciente en cuanto se relacionan con el pensamiento y las actitudes sobre la participación de las sociedades nacionales en la configuración de las relaciones internacionales; en este caso todo ello aplicado al conocimiento de la incidencia de las cuestiones étnicas.

Pero el mayor desafío que provoca el tema es el referido a la obtención de la información necesaria para el conocimiento de las mentalidades colectivas que, por tratarse de sucesos del pasado, no pueden ser observadas directamente; de estas mentalidades 
pueden derivarse actitudes y definiciones políticas, tanto de manera explícita como implícita, tanto las que fueron elaboraciones conscientes como las que fueron el resultado del inconsciente colectivo. Debe resultar interesante la observación de ciertos aspectos de la vida cotidiana, entre ellos los usos, costumbres, hábitos, en los cuales pueda encontrarse una actitud consciente o inconsciente hacia una determinada etnia o cultura (de afirmación, rechazo, defensa, agresión, menoscabo, etc.).

El estudio de las mentalidades, en efecto, implica adentrarse en las conformaciones mentales de individuos anónimos y de grupos comunitarios para entenderlas como tales, desde su propia estructura y desde las propias motivaciones y realidades que las producen. Y esto es válido tanto para los sectores dirigentes, dueños de las decisiones políticas y estratégicas en las relaciones internacionales, como para los portadores de las culturas y poseedores de las etnias cuya incidencia en esas relaciones internacionales queremos conocer.

Una fuente útil aunque discutible para conocer las mentalidades colectivas de tiempos históricos es la prensa escrita, en tanto se dirigía al público para persuadirlo a través de sus artículos y la forma de presentar las noticias a favor de la posición adoptada por sus directivos; también sirve, con las debidas prevenciones, para conocer las opiniones del público que los periódicas reproducían. Uno de sus mayores servicios es la presentación de sucesos públicos, como manifestaciones, mítines, ceremonias, asonadas, etc., lo que permite al investigador sondear los pensamientos colectivos que provocaron tales movilizaciones masivas. Pero está claro que se trata de una fuente que depara sospechas y dudas, en cuanto se trata de conocer esas mentalidades colectivas. ${ }^{33}$

La segunda prioridad, claro está, es la observación y conocimiento de los escenarios geográficos en los que se desarrollaron los acontecimientos estudiados o que fueron objeto de los asuntos

33 Por ejemplo, en la segunda mitad del siglo XIX los diplomáticos españoles destacados en América Latina leían cuidadosamente los periódicos locales y enviaban recortes de los mismos a su Ministro en Madrid, considerándolos de primera importancia como medio para estar al tanto de las opiniones y formar así sus estrategias internacionales. V. al respecto HEREDIA, Edmundo Aníbal. La Guerra de los Congresos. El Pan-Hispanismo contra el Panamericanismo. Córdoba: Junta Provincial de Historia, 2007. Para un tiempo más amplio que el señalado está demostrado el uso frecuente de periódicos por los diplomáticos, a los que pagaban para que publicaran artículos favorables a su causa nacional, y aún financiando periódicos o pancartas con los mismos fines. 
en tratamiento. La toma de conciencia de lo que significa estar observando a otras personas o paisajes, distintos de los que conforman el entorno habitual del observador, es importante para obtener una percepción adecuada y formular una evaluación todo lo objetiva que sea posible. El habitat diferente al propio - en zonas de frontera o marginales, alejadas de los centros urbanos de decisión, o periféricas dentro de de esos espacios urbanos -, agrega otra diferencia y especificidad significativas.

\section{El aporte de la historia de las relaciones internacionales a la explicación de los fenómenos del multi-culturalismo y la regionalización}

Aún no existe consenso general a favor de una u otras de las siguientes opciones de los historiadores. La primera, si los estudiosos del pasado deben ocuparse con preferencia de aquello que tuvo mayor gravitación e influencia en el tiempo que es objeto de su estudio, dentro de un determinado contexto que deben definir; otra, si deben volcar el énfasis hacia aquellos fenómenos pretéritos cuyo conocimiento puede servir para explicar cuestiones acuciantes de la realidad presente, aunque en el momento o tiempo analizado no hubieran alcanzado esos fenómenos alguna relevancia o predominio. Tercero, si los historiadores deben ser indiferentes al respecto, por cuanto así serán más objetivos en las explicaciones del pasado, más "científicos".

Pero si es la realidad actual - con sus apremios, sus demandas, sus realizaciones, sus dramas y sus cuestiones vitales - la que debe impulsar y orientar la búsqueda de explicaciones e interpretaciones de fenómenos históricos, la futura historiografía de las relaciones internacionales latinoamericanas deberá estar dirigida a explicar cómo y por qué se produjeron acontecimientos y procesos tales como la formación de espacios regionales, los proyectos y conatos de formación de bloques regionales, los desplazamientos y asentamientos masivos de poblaciones, la movilidad internacional de las fuerzas de trabajo, la aparición e impacto de ideologías discriminatorias de etnias y culturas, la formación de circuitos, redes, polos y ejes de comunicaciones, la formación de sociedades cosmopolitas y multi-culturales, entre otras. Y todo este conocimiento deberá estar formulado y elaborado de manera tal que sirva para explicar la naturaleza y condiciones de las actuales políticas exteriores de los Estados, las confrontaciones y acuerdos entre las 
naciones para alcanzar niveles de cooperación, de concertación y de integración, las relaciones intra-regionales e inter-regionales, las relaciones multi-laterales.

Circunscribir a los Estados nacionales como principales y aún exclusivos actores de las relaciones internacionales implica también reducir a los Estados de las potencias dominantes la explicación de las relaciones mundiales, y correlativamente excluir de esa explicación a las naciones menores; extender, en cambio, a otros actores la participación en esas relaciones como actores eficientes, da lugar no sólo a completar y enriquecer las interpretaciones, sino también el condicionamiento de aquellas naciones poderosas a las acciones de estos actores, porque el poder de una fuerza superior no es suficiente para anularlos o neutralizarlos.

Para ello la historiografía de las relaciones internacionales en América Latina necesita formular nuevos paradigmas, que pongan distancia con respecto a aquellas urgencias o emergencias dictadas por el impacto, impregnado de terror, de las dos grandes guerras del siglo XX; en cambio, deberá reparar en otras urgencias y emergencias propias de esta región y de estos tiempos, es decir de las últimas décadas de este siglo, como así también de lo que surja de los análisis prospectivos de los cientistas de las relaciones internacionales.

Para determinar esos paradigmas necesita detectar y caracterizar la existencia y acción de otros actores, diferentes de los que han inspirado a los teóricos a partir del rol protagónico y a veces excluyente de los Estados nacionales como máximo aparato decisorio; necesita también reconocer y analizar la gravitación de las peculiaridades distintas de sus espacios regionales; necesita recorrer y diseñar puntualmente su geografía, y a partir de ello interpretar la cartografía con que ha sido ideologizada esa geografía; necesita reconocer e incorporar al esquema de conocimiento la existencia de diversas naciones que están instaladas y conviven o se entrecruzan, con sus diversidades distintivas, dentro de un mismo Estado nacional; del mismo modo, necesita hacerlo con la existencia de una misma nación que se encuentra repartida o esparcida en más de un Estado nacional. Es decir, necesita elaborar conceptos teóricos y metodológicos que atiendan a las cuestiones más significativas de la realidad actual, y que sirvan para ayudar a explicar esa realidad.

En este aspecto, los historiadores latinoamericanos, en general, están adquiriendo una importante ventaja potencial con respecto a 
muchos europeos que desde la historia tanto como de la filosofía política o la sociología siguen intentando explicaciones generalizadas sobre el sentido y significado de la vida social y universal de estos últimos tiempos. En efecto, estos pensadores observan la realidad de su continente y al hacerlo creen que están observando el mundo, o que al menos pueden formular interpretaciones de validez universal; esto se debe a que continúan creyendo que el mundo es apenas una prolongación de su continente, y por tanto creen abarcar en sus especulaciones toda la realidad mundial. Es como si el imperialismo de las naciones del continente europeo, esparcido por todo el orbe, permaneciera aún en las mentes de algunos de sus intelectuales y les inspirara los modos, las formas y aún los contenidos a partir de los cuales observan la vida social. Una parte de responsabilidad les cabe a los intelectuales latinoamericanos, que han seguido sus pensamientos y sus teorías como axiomas, y con ello han dado alas para que los elegidos como paradigmas sigan creyendo en el valor absoluto de su pensamiento.

De todos modos, muchos historiadores latinoamericanos están revirtiendo esta dependencia y, con mayor realismo o con mayor modestia, han comenzado a ser más conscientes en el sentido de que cuando observan la realidad latinoamericana, las explicaciones que de esa observación infieren tienen validez para América Latina, y sólo para América Latina. Este es un buen síntoma.

En fin, se trata de un camino que la historiografía latinoamericana ha comenzado a trazar, pero que necesita aún transitar y trajinar. Este tránsito y este trajín, precisamente, puede ser la mejor contribución que desde la investigación y el estudio de su objeto específico puede hacer a favor de la comprensión de la historia de las relaciones entre las naciones, entre los pueblos y entre las regiones de América Latina, lo cual, a su vez, será una de las bases desde las cuales pueden formularse proyectos plausibles de integración. 